\title{
Cytological and colposcopic evaluation of abnormal cervix
}

\begin{abstract}
Beg $A^{1}$, Islam $\mathrm{MA}^{2}$, Roy $\mathrm{N}^{3}$, Jahan $\mathrm{K}^{4}$, Yasmin $\mathrm{S}^{5}$, Ansari $\mathrm{NP}^{6}$, Nahar $\mathrm{K}^{7}$
Abstract

The second most common cancer among women worldwide is cancer of the cervix commonly develop due to abnormal cervix. To evaluate abnormal cervix by cytology and colposcopy, a prospective study was undertaken among 100 women attending at the colposcopy clinic in Mymensingh Medical College Hospital (MMCH) from January 2008 to July 2008. Cytological and colposcopic evaluation were done in all the patients attending the colposcopy clinic with various complaints like per vaginal discharge, post-coital bleeding, dyspareunia, irregular per vaginal bleeding, backache and abnormal cervix on examination. A biopsy was taken from 53 cases of colposcopically abnormal or clinically doubtful cervices. Cytology and colposcopy findings were compared with the histological results. Study results revealed that 26 apparently healthy cervices in naked eye examination showed abnormal cytology in 8 cases and premalignant and malignant changes was seen in 9 among colposcopically abnormal 11 cases. Among the 40 cases of ectropion, abnormal cytology found in 11 and premalignant and malignant changes in 13 cases. In 11 cases of nabothion cyst, 4 had abnormal cytology and premalignant changes in 2 cases. Among 10 erythema cases, 3 showed abnormal cytology and 6 showed premalignant and malignant changes. One ulcer case revealed malignancy on cytology, colposcopy and histopathology. The other 12 cases, abnormal cytology found in 7 , premalignant and malignant changes found in 8. On cytological examination, abnormal cytology found in 34 cases, among these 26 revealed premalignant and malignant on biopsy report. Out of 66 negative cytological smear cases, 23 colposcopically positive and biopsy showed 13 cases as premalignant and malignant. So, $13 \%$ cases of premalignant and malignant lesion may be overlooked if cytology alone was used for screening.

This study revealed that colposcopy examination significantly reduces false negative cytology. Results of this study concluded that combined procedures enhance diagnostic accuracy.
\end{abstract}

CBMJ 2019 January: vol. 08 no. 01 P: 3-11

Key words: Cervical cancer, cervix, colposcopic evaluation.

\section{Introduction}

Worldwide, cervical cancer accounts for about 500,000 new cases diagnosed and 250,000 deaths every year. Of the new cases, $80 \%$ occur in the less developed countries and in some of these countries, cervical cancer is the commonest cancer in women. This situation is compounded by the fact that in underdeveloped countries $75 \%$ present with an advanced stage, which is the converse of presentation in the developed countries where $75 \%$ present early and cure can be realistically expected. ${ }^{1}$ About $83 \%$ of global cervical cancer cases occur in the developing countries. The highest incidence rates are observed in Sub-Saharan Africa, Melanesia, Latin America and the Caribbean, South Central Asia and South East Asia. An estimation of $30 \%$ of Bangladeshi women
1. Dr. Ayesha Beg, Junior Consultant, Obstetrics and Gynaecology, Upazila Health Complex, Gouripur, Mymensingh.

2. Professor Dr. Mohammad Aminul Islam, Professor of Medicine, CBMCB

3. Dr. Nibedita Roy, Junior Consultant, Obstetrics and Gynaecology, Parangonj 20 Bedded Hospital, Sadar, Mymensingh

4. Dr. Khurshida Jahan, Assistant Professor, Obstetrics and Gynaecology, Mymensingh Medical College, Mymensingh.

5. Dr. Sabina Yasmin, Junior Consultant, Obstetrics and Gynaecology, Upazila Health Complex, Trishal, Mymensingh.

6. Dr. Nazma Parvin Ansari, Associate Professor and Head, Department of Pathology, CBMCB.

7. Professor Dr. Kamrun Nahar, Professor (Rtd), Obstetrics and Gynaecology, Green Life Medical College, Dhaka.

Address of correspondence:

Email:beg_ayesha@yahoo.com Cell No. 01718234415 
suffers from cervical cancer among all female cancers. Early detection can prevent cervical cancer. ${ }^{2}$ Lack of continued effective screening program is a strong barrier for early detection. Worldwide successful cervical cancer prevention is based on an organized screening program. The goal of screening is to detect the pre-invasive stage of the disease and treat it appropriately before it progresses to invasive cervical cancer. In developed countries, initiation and sustenance of cervical screening programs involving screening of sexually active women yearly or once every 3-5 years have resulted in a large decline in cervical cancer incidence and mortality. ${ }^{3-6}$

Eighty percent of women with cervical cancer only come for treatment in advanced stage. As cervical cancer is a major health problem among women of Bangladesh, its screening program has recently been addressed at the national level. It is a type of cancer which can be identified in its precancerous form and if treated successfully, the lesion does not develop into invasive cancer. Cervical cancer is a disease of middle age group and therefore prevention and early diagnosis of this disease will significantly reduce the morbidity and mortality of the productive age group with potentially to contribute to the society. ${ }^{2}$

Invasive squamous carcinoma of the cervix results from the progression of pre-invasive precursor lesions called cervical intraepithelial neoplasaia (CIN). Cervical cytology is presently considered to be the only test known to reduce cervical cancer incidence in organized screening program in developed countries. ${ }^{7}$

The pap smear is an important part of gynaecologic examination. The frequency of the need for this test has been recently revised. Epidemiologic statistics have led the US Preventive Task Force to recommend that for the average woman who has had 3 normal Pap smears, a Pap test every 2 or 3 years is adequate. This recommendation is based on the observation that most cervical cancer is slow growing. ${ }^{8}$ Based on solid evidence, regular screening of appropriate women for cervical cancer with the Papanicolaou (Pap) test reduces mortality from cervical cancer. Screening is effective when started within 3 years after first vaginal intercourse. A number of cervical cancer screening approaches alternative to cervical cytology are described: Liquid based cytology (ThinPrep), automated pap's screening, visual inspection with acetic acid (VIA) and human papilloma virus (HPV) testing. ${ }^{9}$ This study is leading to the investigation to find out the accuracy and efficacy of the procedures as screening tool to detect invasive carcinoma and cervical intraepithelial neoplasia at an earlier date.

\section{Objectives of the Study}

The general objective of the study was to evaluate the colposcopic findings in an abnormal cervix. The specific objectives of the study were to find out the correlation and association between cytological and colposcopic findings and to find out the correlation between cytological findings with the colposcopy directed histopathological findings.

\section{Materials and Methods}

This prospective non-randomized study was conducted at the outpatient department (GOPD) of Gynaecology and Obstetrics in Mymensingh Medical College Hospital (MMCH) from January 2008 to July 2008. The study was carried out among 100 cases of sexually active women attending GOPD of $\mathrm{MMCH}$ presenting with different clinical complaints like per-vaginal discharge, post-coital bleeding, dyspareunia, irregular per-vaginal bleeding, backache and abnormal cervix on examination. Cervical smear and colposcopic examination were taken from all the patients attending the colposcopy clinic. A biopsy was taken from the coloposcopically abnormal or doubtful cases. Clinical history and physical examination were recorded in a prescribed questionnaire. Informed written consent was taken from all study subject after full explanation of the nature, purpose of all procedures needed for study. The ethical principles of the Helsinki Declaration were followed. The inclusion criteria of the study 
were: sexually active women, age 18 or sexual life more than 3 years (whichever comes first) to 55 years, complaints of any abnormal pervaginal discharge or bleeding, post-coital bleeding or dyspareunia and the exclusion criteria were: pregnancy, patient is in menstrual period of cycle, who had hysterectomy or any operative procedure in the cervix, having overt carcinoma of cervix. Data were collected through a direct interview in the preset structured questionnaire form in GOPD of $\mathrm{MMCH}$ who met the study criteria. After collection of required information data were checked and edited manually and analysis was done by Statistical Package for Social Science (SPSS). Then sensitivity, specificity, positive predictive value and negative predictive values were calculated for cytology and colposcopy, after defining true and false positive and negative cases for cytology and colposcopy.

\section{Results}

One hundred cases were enrolled in the study that fulfilled the inclusion criteria. Cervical smear for Papanicolaou stain and colposcopy was done in all cases. Colposcopic guided biopsies were taken from colposcopically suspicious cervices, acetowhite positive and clinically suspicious cases.

Among the study population 18 - 55 years of age, the highest cases belong to age group 28 - 37 years $(58 \%)$, lowest were from age group $>47$ (2\%), $24 \%$ from age group $38-47$ age group and $16 \%$ cases were from age group 18-27. Seventy-seven percent of study cases were educated and $21 \%$ were illiterate. Among the educated patients 35\% achieved secondary, $10 \%$ higher secondary, $10 \%$ graduates, $1 \%$ post graduate, $21 \%$ primary education. Study cases were from two religious groups; between them $88 \%$ were Muslims and $12 \%$ were Hindus. Analysis of the occupation of the cases results $90 \%$ housewives, $7 \%$ government job and 3\% non-government job holder. Large number $(58 \%)$ of cases were from middle class socioeconomic condition. 35\% and $7 \%$ of cases were from lower and upper class respectively. Among the study population $73 \%$ belongs to $1-3$ para and $3 \%$ had $>5$ para. Among the study population $51 \%$ were on oral contraceptive pills, $14 \%$ condom, $4 \%$ injection, $3 \%$ mixed, $2 \%$ IUCD user and $26 \%$ did not use any contraceptive method.

\section{Clinical Characteristics of the Patients}

Per vaginal (PV) discharge was present in 74 cases and absent in 26 cases. Characteristics of PV discharge were analysed and $6 \%$ cases had foul smell, $8 \%$ had blood stained discharge (Table 1). This table also shows 20 patients had irregular per vaginal (PV) bleeding and 80 patients had no history of PV bleeding. Post coital bleeding was present in 19 cases and absent in 81 cases. 59 patient had lower abdominal pain and 48 had dyspareunia and 7 cases had other symptoms like dysuria, vulval pain etc. Clinical presentation showed in the table does not make $100 \%$ because most of the patient presented with more than one complaints. In this study age at marriage has been considered as the age of first intercourse. Majority of study subjects i.e. $34 \%$ were exposed to first coitus at the age between 16-18 years. The mean age of first intercourse is 17.2 years. One case had experienced first intercourse at age 27. Most of the study population had 10-20 years of married life. The mean duration of married life was 16.8 years.

Table 1: Presentation of clinical characteristics of study cases

\begin{tabular}{|c|c|c|}
\hline \multicolumn{2}{|c|}{ Clinical characteristics } & Patients (\%) \\
\hline \multirow{4}{*}{$\begin{array}{c}\text { Per } \\
\text { Vaginal } \\
\text { Discharge }\end{array}$} & No smelled & 39 \\
\cline { 2 - 3 } & Foul smelled & 06 \\
\cline { 2 - 3 } & Blood stained & 08 \\
\cline { 2 - 3 } & Others & 21 \\
\cline { 2 - 3 } & Total & 74 \\
\hline Irregular & Intermenstrual & 17 \\
\cline { 2 - 3 } $\begin{array}{c}\text { per vaginal } \\
\text { bleeding }\end{array}$ & Postmenopausal & 03 \\
\cline { 2 - 3 } & Total & 20 \\
\hline Post coital bleeding & & 19 \\
\hline Dyspareunia & & 48 \\
\hline Lower abdominal pain & & 59 \\
\hline Others & & 07 \\
\hline
\end{tabular}




\section{Examination and procedural findings}

Per speculum examination of the study population attended at the colposcopy clinic revealed $40 \%$ of cases found ectropion, in $10 \%$ cases there were erythema nabothian cyst was found in $11 \%$ of cases, ulcer found 1 cases and $26 \%$ subject had apparently healthy cervix (Table 2). All the patients undergone visual inspection by acetic acid (VIA) in colposcopy, $31 \%$ of cases were found VIA positive and $69 \%$ found VIA negative. Positive colposcopy findings were found in $51 \%$ of study cases. Among them $35 \%$ were low grade $\mathrm{CIN}, 11 \%$ high grade $\mathrm{CIN}, 3 \%$ preclinical invasive carcinoma and $2 \%$ condyloma. Normal findings were found in $29 \%$ of cases and inflammation was found in $20 \%$ of cases. Most of the positive cases were low grade CIN (35\% of all cases). Papanicolaou stain of cervical smear were $36 \%$ inflammation, $23 \%$ mild dysplasia, $14 \%$ of cases normal and both inflammation and squamous metaplasia. Koilocytes were found in 3\% of cases. Inadequate smear and squamous metaplasia was found in $1 \%$ of cases. Moderate and severe dysplasia was present in $5 \%$ and $3 \%$ cases respectively. The total abnormal cytology cases were 34. Biopsy were performed in $53 \%$ of cases and remaining $47 \%$ cases were not indicated according to the colposcopic findings as normal and inflammation was found in $49 \%$ of cases. Two of the cases were biopsied because of suspicious clinical characteristics. Carcinoma was found in 9 cases, CIN1 in 16, CIN2 in 6, CIN3 in 1, inflammation in 13, inflammation plus koilocytic changes in 7 cases and normal biopsy report in 1 case. So, therefore, premalignant and malignant changes were found in 39 cases.
Table 2: Relationship between per speculum examination of cervix and abnormal cytology, colposcopy and biopsy report.

\begin{tabular}{|c|c|c|c|c|}
\hline \multirow{2}{*}{$\begin{array}{l}\text { Per speculum } \\
\text { examination of cervix }\end{array}$} & \multirow{2}{*}{$\begin{array}{l}\text { Abnormal } \\
\text { cytology }\end{array}$} & \multirow{2}{*}{$\begin{array}{c}\text { Colposcopy } \\
\text { positive }\end{array}$} & \multicolumn{2}{|c|}{ Biopsy } \\
\hline & & & \begin{tabular}{|c|} 
Premalignant \\
cases
\end{tabular} & $\begin{array}{l}\text { Malignant } \\
\text { cases }\end{array}$ \\
\hline Apparently healthy (26) & 8 & 11 & 7 & 2 \\
\hline Ectropion (40) & 11 & 20 & 12 & 1 \\
\hline Nabothian cyst (11) & 4 & 5 & 2 & 0 \\
\hline Erythema (10) & 3 & 6 & 3 & 3 \\
\hline Ulcer (1) & $\overline{1}$ & $\overline{1}$ & 0 & 1 \\
\hline Others (12) & 7 & 8 & 6 & 2 \\
\hline Total (100) & 34 & 51 & 30 & 9 \\
\hline
\end{tabular}

Table 2 shows that among the apparently healthy cervix (26) -abnormal cytology was found in 8 cases and 11 cases found colposcopically positive and biopsy report showed premalignant and malignant changes in 9 cases. Ectropion was found in 40 cases. Out of these abnormal cytology found in 11 cases, colposcopically positivity found in 20 cases and histopathology showed premalignancy \& malignancy in 13 cases. Nabothian cyst was present in 11 cases. Among these 4 had abnormal cytology, 5 cases were diagnosed as low grade CIN on colposcopic examination. Biopsies revealed premalignant changes in 2 cases. Erythema was found in 10 cases Out of these 3 cases had abnormal cytology, 6 cases diagnosed as positive in colposcopic examination, and histopathology revealed malignancy and premalignancy in 6 cases. Ulcer was found in 1 case which revealed malignancy on colposcopy, cytology and histopathology. Among the other cases, 12 abnormal cytology was found in 7 cases, colposcopically positive cases found in 8 cases, biopsy revealed premalignant and malignant changes in 8 cases.

Table 3 shows the relationship between Pap's stain, colposcopic diagnosis and biopsy report. Total 53 cases were undergone for biopsy procedure. Among these cytology positive cases were 30 which revealed on biopsy as 3 koilocytic changes, 13 CIN1, 5 CIN2 and 5 carcinomas. Three cases showed normal in cytology which on 
biopsy revealed 1 normal and 2 as carcinoma. Inflammation and inflammation plus squamous metaplasia was found in 20 cases which on biopsy revealed 9 inflammations, 3 CIN1, 1 CIN2, 1 CIN3, 2 carcinomas. Again there is relationship between findings of colposcopic diagnosis and biopsy report. Here colposcopy positive cases were 51 . Colposcopy revealed 2 normal which on biopsy showed 1 normal and 1 CIN2; 35 low grade CIN on colposcopy revealed 13 inflammations, 16 CIN1, 1 carcinoma and 5 inflammations plus koilocytic changes on biopsy; in colposcopy 11 high grade CIN revealed 5 CIN2, 1 CIN3, and 5 carcinoma on biopsy; 3 preclinical invasive carcinoma on colposcopy revealed as carcinoma on biopsy; 2 condyloma in colposcopy were found same on biopsy. In summary, out of 51 colposcopy positive cases, 38 cases found as malignancy and premalignancy.

Cytologically abnormal cases (i.e., cytologically positive) was 34 and biopsy proved positive was 26 cases. So, 26 cases were true positive and false positive cases was 8 . Cytologically negative cases was 66 , among these biopsy was done in 23 cases and biopsy revealed 13 cases as premalignant and malignant changes and other 10 regarded as nomal. So, false negative cases were 13 and true negative cases were 53. Colposcopically positive cases were 51 which on biopsy proved premalignancy and malignancy was 38 . So, true positive cases were 38 and false positive cases were 13. Colposcopically negative cases were 49, among these 2 cases were underwent for biopsy. One case revealed premalignancy on biopsy. So the true negative was 48 cases and false negative was 1 case. The sensitivity and specificity of cytology were $66.66 \%$ and $86.88 \%$ respectively. The positive predictive value was $76.47 \%$ and negative predictive value was $86.36 \%$. The sensitivity of colposcopic examination was $97.43 \%$ and specificity was $78.68 \%$. The positive predictive value was $74.50 \%$ and negative predictive value was $98 \%$. Significant
Table 3: Relationship between findings of pap's stain of cervical smear, colposcopic diagnosis and biopsy report

\begin{tabular}{|c|c|c|c|c|c|c|c|c|}
\hline \multirow[b]{2}{*}{$\begin{array}{l}\text { Pap's stain of } \\
\text { cervical smear }\end{array}$} & \multirow[b]{2}{*}{$\begin{array}{l}\text { Colposcopic } \\
\text { diagnosis }\end{array}$} & \multicolumn{6}{|c|}{ Biopsy } & \multirow[b]{2}{*}{ Total } \\
\hline & & 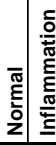 & ¿ & ב & $\begin{array}{l} \\
m \\
z \\
0\end{array}$ & 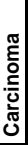 & 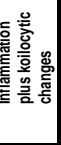 & \\
\hline \multirow{4}{*}{ Normal } & Low grade CIN & 1 & & & & & & 1 \\
\hline & High grade CIN & 0 & & & & 1 & & 1 \\
\hline & $\begin{array}{c}\text { Preclinical invasive } \\
\text { carcinoma }\end{array}$ & $\overline{0}$ & & & & $\begin{array}{l}1 \\
2\end{array}$ & & 1 \\
\hline & Total & 1 & & & & & & 3 \\
\hline \multirow{4}{*}{ Inflammation } & Low grade CIN & 7 & 2 & 0 & 0 & 0 & 2 & 11 \\
\hline & High grade CIN & $\overline{0}$ & 0 & 1 & 1 & 1 & 0 & 3 \\
\hline & Condyloma & 0 & 0 & 0 & 0 & 0 & 1 & 1 \\
\hline & Total & 7 & 2 & 1 & 1 & 1 & 3 & 15 \\
\hline \multirow{3}{*}{ Koilocytes } & Low grade CIN & & & & & & 2 & 2 \\
\hline & Condyloma & & & & & & 1 & 1 \\
\hline & Total & & & & & & 3 & 3 \\
\hline \multirow{4}{*}{ Mild dysplasia } & Normal & \begin{tabular}{l|l}
10 \\
\end{tabular} & 0 & 0 & & 0 & & 1 \\
\hline & Low grade CIN & \begin{tabular}{l|l}
03 \\
\end{tabular} & 13 & 0 & & 1 & & 17 \\
\hline & High grade $\mathrm{CIN}$ & 00 & 0 & 1 & & 0 & & 1 \\
\hline & Total & \begin{tabular}{|l|l|}
1 & 3 \\
\end{tabular} & 13 & 1 & & 1 & & 19 \\
\hline \multirow{3}{*}{$\begin{array}{l}\text { Moderate } \\
\text { dysplasia }\end{array}$} & Normal & & & 1 & & 0 & & 1 \\
\hline & High grade CIN & & & 3 & & 1 & & 4 \\
\hline & Total & & & 4 & & 1 & & 5 \\
\hline \multirow{3}{*}{$\begin{array}{l}\text { Severe } \\
\text { dysplasia }\end{array}$} & High grade CIN & & & & & 1 & & 1 \\
\hline & $\begin{array}{c}\text { Preclinical invasive } \\
\text { carcinoma }\end{array}$ & & & & & $\begin{array}{l}2 \\
3\end{array}$ & & 2 \\
\hline & Total & & & & & & & 3 \\
\hline \multirow{3}{*}{$\begin{array}{c}\text { Both } \\
\text { inflammation and } \\
\text { squamous metaplasia }\end{array}$} & Low grade CIN & 2 & 1 & & & 0 & 1 & 4 \\
\hline & High grade CIN & 0 & 0 & & & 1 & 0 & 1 \\
\hline & Total & $\overline{2}$ & 1 & & & - & 1 & 5 \\
\hline
\end{tabular}

Table 3 shows the relation between the findings of cytology, colposcopy diagnosis and biopsy report. 
Table 4: Correlations among per speculum examination, cytology, and colposcopy and biopsy report

\begin{tabular}{|c|c|c|c|c|c|}
\hline & & $\begin{array}{c}\text { Per speculum } \\
\text { examination } \\
\text { of cervix }\end{array}$ & $\begin{array}{c}\text { Pap's stain } \\
\text { of cervical } \\
\text { smear }\end{array}$ & $\begin{array}{c}\text { Colposcopic } \\
\text { diagnosis }\end{array}$ & $\begin{array}{c}\text { Biopsy } \\
\text { report }\end{array}$ \\
\hline $\begin{array}{c}\text { Per speculum } \\
\text { examination } \\
\text { of cervix }\end{array}$ & Pearson Correlation & 1 & .161 & $.205\left(^{*}\right)$ & .044 \\
\cline { 2 - 6 } & Sig. (2-tailed) & & .109 & .041 & .755 \\
\hline \multirow{2}{*}{$\begin{array}{c}\text { Pap's stain } \\
\text { of cervical } \\
\text { smear }\end{array}$} & Pearson Correlation & .161 & 1 & .144 & -.039 \\
\cline { 2 - 6 } & Sig. (2-tailed) & .109 &. & .153 & .779 \\
\hline \multirow{2}{*}{$\begin{array}{c}\text { Colposcopic } \\
\text { diagnosis }\end{array}$} & $\mathrm{N}$ & 100 & 100 & 100 & 53 \\
\cline { 2 - 6 } & Searson Correlation & $.205\left(^{*}\right)$ & .144 & 1 & $\left..5366^{* *}\right)$ \\
\hline \multirow{2}{*}{$\begin{array}{c}\text { Biopsy } \\
\text { report (2-tailed) }\end{array}$} & .041 & .153 &. & .000 \\
\cline { 2 - 6 } & Pearson Correlation & .044 & -.039 & $.536\left(^{* *}\right)$ & 1 \\
\cline { 2 - 6 } & Sig. (2-tailed) & .755 & .779 & .000 &. \\
\hline & $\mathrm{N}$ & 53 & 53 & 53 & 53 \\
\hline
\end{tabular}

* Correlation is significant at the 0.05 level (2-tailed).

** Correlation is significant at the 0.01 level (2-tailed).

correlation is seen between colposcopic diagnosis and biopsy at the 0.01 level and between speculum examination of cervix and colposcopic examination at 0.05 levels. Negative correlation is seen between cytological and colposcopic and cytological and histopathological examination.

\section{Discussion}

This study data confirms that colposcopic examination is a standard technique for evaluation of abnormal cervices. These data also confirm that combined evaluation by cytology, colposcopy and biopsy is superior than single procedure. These data are in agreement with recently published papers. ${ }^{10-13}$ In this study positive findings were referred to presence of cervical intraepithelial neoplasia (CIN) 1, 2, 3; carcinoma and koilocytosis. Negative findings refer to normal findings or inflammatory changes. Biopsy and histopathological examination was regarded as reference test. In cytology, the dysplasia (mild, moderate and severe) and koilocytic changes were taken as abnormal cytology. The maximum cases of the study (58\%) belong to the 28-37 year age group, the peak age of carcinoma incidence are included into this age group. Seventy-seven percent of study populations were educated. Among the study population, $88 \%$ were Muslims 90\% were housewives and 10\% were in jobs, $58 \%$ from middle class socioeconomic strata. The majority of women $(73 \%)$ had $1-3$ para. $14 \%, 27 \%$ and $4 \%$ had history of abortion, MR and D\&C respectively. Among the study women 51\% were oral pill users and $26 \%$ did not use any contraceptives. The mean age at first intercourse in study population was 17.2 years, $34 \%$ were exposed to first coitus at the age between $16-18$ years and their duration of married life 10-20 years in most of the cases, the mean duration was 16.8 years. The majority of cases attended at the colposcopy clinic with more than one clinical complaints. Among these $74 \%$ patient had per vaginal discharge, $20 \%$ patients had irregular per vaginal bleeding which was intermenstrual type in $85 \%$ and postmenopausal in $15 \%$ cases. Post coital bleeding was present in 19\%, lower abdominal pain in $59 \%$, dyspareunia in $48 \%$ and other symptoms like dysuria, vulval pain etc. in $7 \%$ cases (Table 1). Shalini et al in (1998) in his study showed the relation with clinical features. Per speculum examination found $40 \%$ ectropion, $10 \%$ erythema, $11 \%$ nabothian cyst, $1 \%$ ulcer and $26 \%$ cases had apparently healthy cervix. ${ }^{14}$ VIA was done in all cases as prerequisite of colposcopic examination. And found positive in 31 cases and negative in 69 cases. On colposcopic examination, positive cases found in $51 \%$ cases. These were as low grade $\mathrm{CIN}$ in $35 \%$ cases, high grade CIN in $11 \%$ cases, condyloma in $2 \%$ cases and preclinical invasive carcinoma in $3 \%$ cases. On cytological examination, $23 \%, 5 \%$ \& 3\% cases found mild, moderate \& severe dysplasia respectively. Koilocytic change founds in $3 \%$ cases. Biopsy was done in $53 \%$ cases according to colposcopic and clinical findings. Among these cases biopsy report shows normal in $1.9 \%$ (1), inflammation in $24.5 \%(13)$, CIN 1 in $30.2 \%$ (16), CIN 2 in $11.3 \%(6)$, CIN3 in 1.9\% (1), 
carcinoma in 17\% (9) and both inflammation \& koilocytic changes in $13.2 \%$ (7) cases. On naked eye examination, among the apparently healthy cervix (26) -abnormal cytology was found in 8 cases and 11 cases found colposcopically positive and biopsy report showed premalignant and malignant changes in 9 cases. Ectropion was found in 40 cases. Out of these abnormal cytology found in 11 cases, colposcopically positivity found in 20 cases and histopathology showed premalignancy \& malignancy in 13 cases. Nabothian cyst was present in 11 cases. Among these 4 had abnormal cytology, 5 cases were diagnosed as low grade CIN on colposcopy examination. Biopsies revealed premalignant changes in 2 cases. Erythema was found in 10 cases. Out of these 3 cases had abnormal cytology, 6 cases diagnosed as positive in colposcopic examination, and histopathology revealed malignancy and premalignancy in 6 cases. Ulcer was found in 1 case which revealed malignancy on colposcopy, cytology and histopathology. Among the other cases 12 abnormal cytology was found in 7 cases, colposcopically positive cases found in 8 cases, biopsy revealed premalignant and malignant changes in 8 cases (Table 2). On cytological examination, among the 14 normal findings 2 cases were diagnosed as carcinoma on biopsy. Inflammation founds in 36 cases, among these 15 were colposcopically positive and on biopsy 7 cases were as premalignant and 1 had malignant changes. Cytology reveals both inflammation and squamous metasplasia in 14 cases and biopsy proved 1 case as CIN 1, 1 koilocytic change and 1 was invasive carcinoma. So, finally cytology negative cases were 66 and among these 23 were colposcopically positive and biopsy was done. Among the negative cytological cases (66), 9 cases were diagnosed as premalignant and 4 as malignant cases. So $13 \%$ cases of $\mathrm{CIN}$ and malignant lesions may be overlooked if cytology alone is used for screening. This information of the study is closely correlated with the study of Pete I et al (1998). ${ }^{11}$ In this study findings of carcinoma in negative smear also correlate with the study of Naujoks $\mathrm{H}$ et al (1976). ${ }^{13}$

In cytology, koilocytic change was found in 3 cases which were and biopsy proved them as koilocytosis (Table 3). Twenty three cases had mild dysplasia on cytology. Biopsies were done in 19 cases where found 13 cases as CIN 1, 1 case as CIN2 and 1 as carcinoma. Moderate and severe dysplasia found in 8 cases. Biopsy confirms these as CIN 2 in 4 cases and carcinoma in 4 cases. This indicates that high grade CIN evaluation is satisfactory with all the procedures. The above findings revealed that the cytologically abnormal cases were 34 , among these 28 was colposcopically positive and biopsy was done in 30 cases and 26 cases was revealed as malignant and premalignant cases on biopsy report. The result of this study shows that satisfactory colposcopic evaluation is a highly accurate method of evaluation of abnormal cervical cytologic smear. Similar findings are observed in the study of Talebian $\mathrm{F}$ et al (1977). ${ }^{12}$ In this study the sensitivity of cytological examination was $66.66 \%$ and specificity was $86.88 \%$. The positive predictive value was $76.47 \%$ and negative predictive value was $80.30 \%$. These findings are approximately similar to standard study value. Different studies showed cytological accuracy within one level of histological findings to about $83 \%$ and $88 \%$. Sensitivity of conventional pap is ranging from $60 \%$ to $90 \%{ }^{7}$ So, the sensitivity of my study is within the international standard range.

Nasreen Akhter in her study in 2005 revealed $100 \%$ sensitivity and specificity of pap's test, value is much higher than my study. ${ }^{15}$ Because she took pap's test as reference test, but in my study histopathology was the reference test. DiBonito et al in 1993 in Italy observed in their study that the overall sensitivity of cytology was $76.3 \%$, positive predictive value was $80.2 \%$. Specificity was $93 \%$ and negative predictive value was $91.3 \%{ }^{16} \mathrm{My}$ study's value is lower than his value. The sensitivity of colposcopic examination was 
$97.43 \%$ and specificity was $78.68 \%$. The positive predictive value was $74.51 \%$ and negative predictive value was $98 \%$. Kazi Salma Rezina in her study in 2006 in Bangladesh, colposcopy and biopsy revealed that the sensitivity and specificity of colposcopic examination was $100 \%$ and $84.37 \%$ respectively which is closely approximate with my study. ${ }^{10}$ Pete $I$ et al in 1998 in Hungary in a retrospective study, the cytologic and colposcopic findings were compared with the histological results. ${ }^{11}$

Sensitivity and specificity rates of cytology were $47 \%$ and $77 \%$, respectively and corresponding figures for colposcopy were $87 \%$ and $15 \%$ which were lower than my study because in his study $50 \%$ of CIN was associated with abnormal colposcopy where the cytology was negative. But in this study it was $13 \%$. In a study of Lozowski MS et al in 1982 evaluate the accuracy of cytologic and colposcopic findings (alone and in combination) in detecting preclinical lesion of the uterine cervix, diagnoses made in 170 consecutive patients referred for colposcopic examination at Nassau Hospital because of an abnormal Papanicolaou smear were reviewed. ${ }^{17}$ They found that of the investigative methods available prior to biopsy, a combined cytologic and colposcopic evaluation is preferred since it is highly accurate in predicting the degree of severity of a lesion $(84.6 \%$ of all cases reviewed) and, in our experience, eliminates the the problem of false negatives, which are encountered when either method is used to the exclusion of the other.

Table 4 shows the correlation among naked eye examination of cervix, pap's stain, colposcopy and biopsy. It is seen that there is significant correlation between colposcopic diagnosis and biopsy at the 0.01 level. Significant correlation also seen between speculum examination of cervix and colposcopic examination at 0.05 level. But there is negative correlation between cytological and colposcopic examination and also between cytological and histopathological examination.

\section{Limitations of the study}

It was a dependable study. For cytological report needs to depend upon cytopathologist and for colposcopic examination depend on gynaecologist trained in colposcopy. Regarding cytopathology technical error is more. Cases that were found negative in colposcopy were excluded from biopsy, so we may have missed some false negative values for colposcopy. This study was further strengthened by comparing the study with other similar study where all the cases have undergone biopsy including the cytology negative and colposcopy negative cases.

\section{Conclusion}

On the basis of this study following conclusion can be drawn:- incidence of preinvasive disease of cervix is high among women in outpatient department coming with different gynaecological complaints, any abnormality in cytology should be evaluated by colposcopic examination followed by biopsy, periodic clinical examination of cervix is very much important, it is very much important that every women should gone through the cervical screening according to ACS guideline, naked eye examination findings of cervix sometimes do not correlate with cytological findings, cytology by Pap's though standard procedure, is expensive and required many trained personnel, laboratory and logistic support. Therefore, it is suggested that- regular and periodic cervical screening for early detection of cancer cervix must be done, clinically suspicious cervix should have evaluated by adjunct of cytology and colposcopy as the combined use of cytology and colposcopy enhancing diagnostic accuracy in preclinical lesion of cervix, facilities for colposcopy should present in all medical colleges and district hospitals, all the physicians should have referral knowledge for screening of cervical cancer, various awareness programs on cervical cancer should be arranged at national level. 


\section{References:}

1. Shafi MI. Premalignant and Malignant disease of the cervix. In: Edmond D.K, ed. Dewhurst's Text book of Obstetrics and Gynaecology 7th edn. Blackwell publisling 2007, 614-624.

2. Zaman N. Human Papilloma Virus and Cervical Cancer. OGSB newsletter, issue-4 June, 2007.

3. Hekama M, Chamberlain J, Day NE, Miller $A B$, Prorok $P C$. Evaluation of screening programmes for gynaecological cancer. $\mathrm{Br} J$ Cancer. 1985 Oct: 52 (4): 669-73.

4. Hakama M, Miller AB, Day NE eds. Screening for cancer of the uterine cervix. Lyon, IARC scientific Publications. No 76, 1986.

5. Control of cancer of the cervix uteri. $A$ WHO meeting. Bull World Health Organ. 1986; 64 (4): 607-18.

6. Miller $A B$, Chamberlain J, Day NE, Hakama $M$, Prorok PC. Report on a Workshop of the UICC projection on Evaluation of Screening for Cancer. Int J Cancer. 1990 Nov 15: 46 (5): 761-9.

7. World Health Organizaton. Cervical cancer screening in developing countries. Report of a WHO consultation 2001.

8. Christne H. Holschneider. Premalignant and Malignant Disorder of the Uterinte cervix. In: Decherney A. $H$, Nathan L, Goodwin T. M, Laufer $N$ end. Current Diagnosis \& Treatment Obstetries \& Gynaccology 10th edn. MC Graw Hill Companics. 2007:833-854.

9. Maria Julieta V, Germar MD. Visual inspection with acetic acid as a cervical cancer screening tool for developing countries. Department of Reproductiove Health and Research. Geneva Foundation for Medical Education and Research.

10. Rezina KS. Comparative study of VIA, Colposcopy, Cervical Biopsy in Diagnosis of carcinoma Cervix, Library, Bangladesh College of Physicians \& Surgeons, 2006.

11. Pete I, Toth V, Bosze $P$. The value of colposcopy in screening cervical carcinoma. Eur J Gynaecol Oncol. 1988;19(2): 120-2.
12. Talebian $F$, Shayan $A$, Krumholz $B A$, Palladino VS, Mann LI. Colposcopic evaluation on patients with abnormal cervical cytology. Obstet Gynecol. 1977 Jun; 49(6):670-4.

13. Naujoks $H$, Leppien $G$, Rogosaroff- Fricke $R$. Negative smear in cervical carcinoma in situ (author's transl). Geburtshilfe Frauenheilkd. 1976 Jul; 36(7):570-5.

14. Shalini $R$, Amita $S$, Neera MA. How alarming is post-coital bleeding - a cytologic, colposcopic and histopathologic evaluation. Gynecol Obstet Invest. 1998;45(3):205-8.

15. Akhter N. Visual Inspection of Cervix by acetic acid (VIA) and Pap's smear for screening of cervical cancer - A comparative study. Dissertation Library, Bangladesh College of Physicians \& Surgeons, 2005.

16. DiBonito $L$, Falconieri $G$, Tomasic $G$, Colautti I, Bonifacio D, Dudine S. Cervical cytopathology. An evaluation of its accuracy based on cytohistologic comparison. Cancer 1993 Nov 15; 72(10):3002-6.

17. Lozowski MS, Mishriki Y,Talebian F, Solitare $G$. The combined use of cytology and colposcopy in enhancing diagnostic accuracy in preclinical lesion of the uterine cervix. Acta Cytol. 1982 May-Jun;26(3):28591. 